\title{
Plasma Ion Source with an Internal Evaporator
}

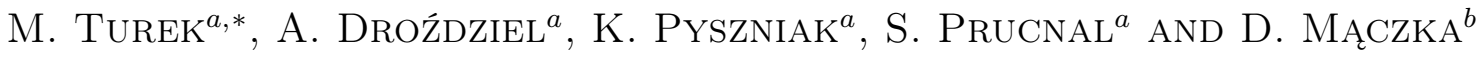 \\ ${ }^{a}$ Institute of Physics, Maria Curie-Skłodowska University in Lublin \\ pl. M. Curie-Skłodowskiej 1, 20-031 Lublin, Poland \\ ${ }^{b}$ Institute of Atomic Energy, 05-400 Otwock/Świerk, Poland
}

\begin{abstract}
A new construction of a hollow cathode ion source equipped with an internal evaporator heated by a spiral cathode filament and arc discharge is presented. The source is especially suitable for production of ions from solids. The proximity of arc discharge region and extraction opening enables production of intense ion beams even for very low discharge current $\left(I_{\mathrm{a}}=1.2 \mathrm{~A}\right)$. The currents of $50 \mu \mathrm{A}\left(\mathrm{Al}^{+}\right)$and $70 \mu \mathrm{A}\left(\mathrm{Bi}^{+}\right)$were obtained using the extraction voltage of $25 \mathrm{kV}$. The source is able to work for several tens of hours without maintenance breaks, giving possibility of high dose implantations. The paper presents the detailed description of the ion source as well as its experimental characteristics like dependences of extracted currents and anode voltage on anode and cathode currents.
\end{abstract}

PACS: 07.77.Ka, 34.80.Dp, 61.72.uj

\section{Introduction}

Ion implantation, offering precise control of the dopant depth profile, is one of the most important techniques enabling modification of optical and electronic properties of solids. One of the clues of this well-established method is obtaining intense and stable ion beams. This is a challenge especially in the case of refractory substance, like rare earths, which are of great interest due to their specific electronic, optical and magnetic properties $[1,2]$.

There are several ways [3] enabling production of ions of non-gaseous elements by feeding vapors into the ionization chamber, each having its advantages and drawbacks. The very popular method is using an external oven producing vapor for hollow cathode, electron cyclotron or any other kind of ion source. The weak spot of such solution is an effective vapor transport, as well as low vapor pressure of non-volatile substances. The second difficulty could be overcome by using alloys of low melting point [4]. Another popular group of feeding material are volatile compounds like halides or organometallic compounds [5]. One should, however, have in mind that they are highly reactive and toxic. Sputtering of feeding material placed in the source could be done by ions $[6,7]$ or electrons [8]. Mechanical sputtering of metals was also employed [9], but the main drawback of this approach was a poor stability of extracted current. The great advantage of laser ablation ion sources $[10,11]$ is the fact that they can ionize any solid material and give possibility of effective production of multiply charged ions. Finally, vapors of high melting point materials could be produced using discharge plasma for heating a container placed inside the ionization chamber.

* corresponding author; e-mail: mturek@kft.umcs.lublin.pl
This approach was successfully applied in our previous design [12, 13], combining features of Nielsen [3] and metal vapor arc discharge (MEVVA [14]) ion sources. The molybdenum crucible, often called an evaporator, is surrounded by a spiral cathode. The arc discharge between the cathode and cylindrical anode heats the ionizer, making the feeding substance vaporize. Atoms are ionized in the discharge by energetic electrons. Ion source of that kind provides high extracted currents of solid ions, e.g. $80 \mu \mathrm{A}$ of $\mathrm{Al}^{+}, 10 \mu \mathrm{A}$ of $\mathrm{Cr}^{+}, 100 \mu \mathrm{A}$ of $\mathrm{As}^{+}$. The current values were obtained using $25 \mathrm{kV}$ extraction voltage and measured approximately half an hour after the discharge is initialized - in many cases (like Mn and In) extracted currents grow even twice as large with the source operation time. It is worth mentioning that the source is able to produce $\approx 25 \mu \mathrm{A}$ of $\mathrm{Eu}^{+}$using $\mathrm{EuCl}_{3}$ and $\mathrm{H}_{2}$ to prevent formation of $\mathrm{EuOCl}$.

The paper presents a new construction based on the idea of an internal evaporator. The evaporator is placed inside a hollow cathode and surrounded by a spiral filament. The arc discharge region, where ion production takes place, is as close as possible to the extraction opening. That factor could lead to the increase of extracted currents, compared to the cylindrical anode source [12, 13]. Additionally, the front part of the source, being an anode, is negatively biased and attracts positive ions. Another modification is funnel-like shape of the extraction opening, making the penetration of the extraction field easier.

The detailed description of the ion source construction is given in the paper. The preliminary results obtained for $\mathrm{Al}$, In and noble gases are presented - namely the dependences of extracted ion currents on anode and cathode currents as well as on the magnetic field of the electromagnet that surrounds the source. The changes of anode voltage due to these factors are also shown and discussed. 


\section{Construction of the source}

The cross-section of the source is shown in Fig. 1. The hollow cathode chamber, made of molybdenum, has an inner diameter of $14 \mathrm{~mm}$ and the length of $20 \mathrm{~mm}$. The chamber consists of two cylindrical parts separated by an insulator made of boron nitride. The two parts of the hollow cathode chamber are also mounts of the spiral cathode filament. The filament has an external diameter of $7 \mathrm{~mm}$ and is made of tungsten wire. A cathode current $I_{\mathrm{c}}$ may be varied up to $\approx 38 \mathrm{~A}$. The typical lifetime of the cathode is $50 \mathrm{~h}$ and depends on the filament material (it is extended e.g. for thorium enriched tungsten). The molybdenum evaporator is placed inside the cathode, surrounded by a spiral filament. It has a form of a long $(\approx 30 \mathrm{~mm})$ slim tube. The external diameter is $3 \mathrm{~mm}$. The crucible is filled with a feeding substance (powder or small lumps). The evaporator is heated mainly by the cathode filament. Discharge also provides heat, but the distance between the region of arc discharge and the evaporator is significantly larger than in our previous design. The evaporator temperature is also controlled (depending on the melting point of the feeding substance) by changing the depth of the crucible's insertion in the chamber.

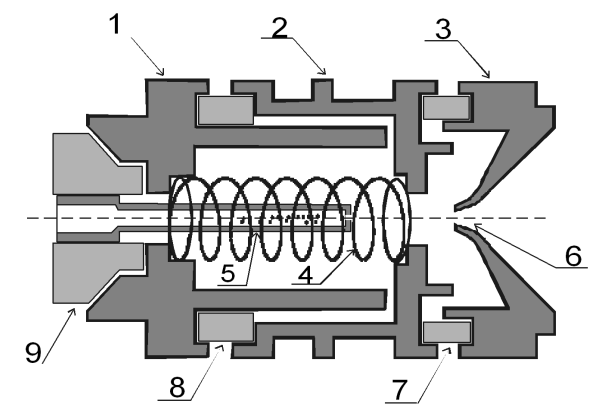

Fig. 1. Schematic view of the ion source: 1,2 - cathode chamber parts, 3 - anode, 4 - filament, 5 evaporator, 6 - extraction hole in the anode, $7,8,9$ — insulators.

The arc discharge burns in the region between a tip of funnel-shaped anode and a front part of cathode mount. The discharge ignition is done by applying a voltage of approximately $90-110 \mathrm{~V}$. It should be mentioned that later on, when the discharge is established, the anode voltage $U_{\mathrm{a}}$ is lower $(20-60 \mathrm{~V})$. Vapors of the feeding substance reach the discharge, where neutral atoms are ionized by electrons. The whole chamber of the source is surrounded by an axial electromagnet coil compensating the field from the spiral filament. When the ions produced by electron impact ionization arrive near the anode, they are caught by the electric field and pulled out of the source through the extraction hole of $1 \mathrm{~mm}$ diameter. The shape of the anode makes the penetration of extraction field easier. Due to this (and small distance between the discharge and extraction hole) one may expect that the extracted currents could be larger than in the case of our earlier construction $[12,13]$.

\section{Experimental results}

During the development stage the source was tested mainly using noble gases. Current vs. voltage characteristics were measured for $\mathrm{He}$, Xe and $\mathrm{Kr}$ using the Faraday cup attached to the extraction electrode. Total extracted currents are shown in Fig. 2. The results were obtained for the discharge current $I_{\mathrm{a}}=1 \mathrm{~A}$. In all cases $I_{\text {tot }}$ grows fast with $U_{\text {ext }}$, as predicted by the Child-Langmuir formula. For $U_{\text {ext }}$ larger than $12 \mathrm{kV}(\mathrm{Ne})$ or $17 \mathrm{kV}(\mathrm{He}$ and $\mathrm{Xe}$ ) saturation is observed, meaning that the $I_{\text {tot }}$ is limited by the rate of ion production in the source. The clue is that currents are approximately 2 or 3 times larger than those obtained for the Nielsen-like type ion source, which was the base for the construction described in $[12,13]$. It should be mentioned here that during the presented experiments $I_{\mathrm{a}}$ was limited to $1.2 \mathrm{~A}$.

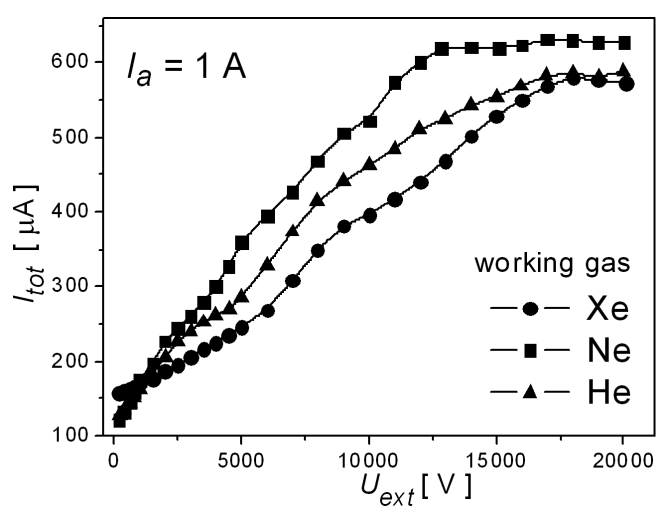

Fig. 2. Current vs. voltage curves for noble gases.

The currents of separated beams $I_{\text {ion }}$ (after passing an electromagnet and accelerating system) were determined for $I_{\mathrm{a}}=1.1 \mathrm{~A}$ and the accelerating voltage $U_{\text {acc }}=75 \mathrm{kV}$. Ion currents were $80 \mu \mathrm{A}\left(\mathrm{He}^{+}\right), 55 \mu \mathrm{A}\left(\mathrm{Xe}^{+}\right)$and $110 \mu \mathrm{A}$ $\left(\mathrm{Ar}^{+}\right)$. The values of $I_{\text {ion }}$ yielded by our previous construction (the same conditions) were $15 \mu \mathrm{A}, 20 \mu \mathrm{A}$ and $40 \mu \mathrm{A}$, respectively. The vantage of the novel design with arc discharge near the extraction opening is clear.

The source was also tested using $n$-butane, in order to check whether ions with two or more $\mathrm{C}$ atoms could be obtained. The result was $80 \mu \mathrm{A}$ for the ions having mass of 30 a.m.u. (most probably $\mathrm{C}_{2} \mathrm{H}_{6}^{+}$).

During the tests with solids the evaporator was loaded with $\approx 100 \mathrm{mg}$ of $\mathrm{Al}$ or $250 \mathrm{mg}$ of $\mathrm{In}$. The influence of $I_{\mathrm{a}}, I_{\mathrm{c}}$ and magnetic field $B$ of the electromagnet on $I_{\text {ion }}$ was under investigation (see Fig. 3 ). For both substances there is a fast increase of $I_{\text {ion }}$ with $I_{\mathrm{a}}$ due to the increasing plasma density, which leads to more effective ionization. Moreover, the arc discharge takes part in the heating of the evaporator - the larger is $I_{\mathrm{a}}$, the higher is the evaporator's temperature. Let us note that $I_{\mathrm{a}}$ values are too small to observe saturation of $I_{\text {ion }}\left(I_{\mathrm{a}}\right)$ curves, which were observed during the tests of our earlier construction. This effect was due to the decrease of $U_{\text {a }}$ with the increasing $I_{\mathrm{a}}$ and less effective electron ionization. 
In the considered case there is rather an increase of $U_{\mathrm{a}}$ with $I_{\mathrm{a}}$. It is expected that for larger $I_{\mathrm{a}}(3$ or $4 \mathrm{~A})$ both the reduction of $U_{\mathrm{a}}$ and saturation of $I_{\mathrm{ion}}\left(I_{\mathrm{a}}\right)$ curves will be observed.
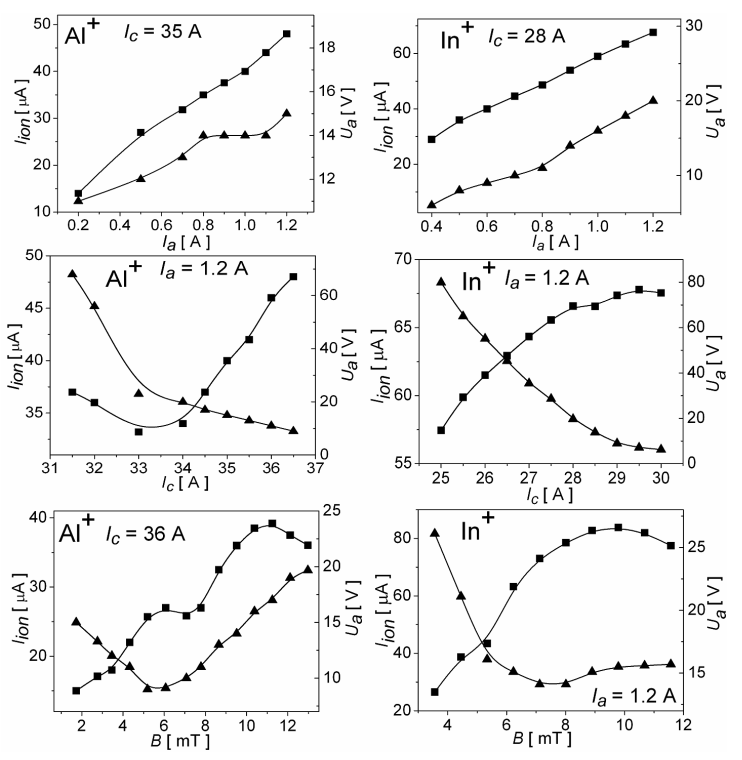

Fig. 3. Ion current (squares) and anode voltage (triangles) for $\mathrm{Al}^{+}$and $\mathrm{In}^{+}$as functions of discharge current $I_{\mathrm{a}}$, cathode current $I_{\mathrm{c}}$ and magnetic field flux $B$.

The evaporator is heated mainly by a cathode filament. Hence, $I_{\text {ion }}$ should rise with $I_{\mathrm{c}}$. This is confirmed by the experimental data - currents rise very fast with $I_{\mathrm{c}}$. Let us note that $\mathrm{Al}$ (melting point $933 \mathrm{~K}$ ) requires much higher $I_{\mathrm{c}}$ than indium $(430 \mathrm{~K})$. In that case one can see saturation of $I_{\text {ion }}\left(I_{\mathrm{c}}\right)$ curve, which may be explained by the fact that the filament is a source of primary electrons. Increasing concentration of electrons has two consequences: it enhances the ionization probability but also causes the reduction of $U_{\mathrm{a}}$. As previously, the reduction of $U_{\mathrm{a}}$ and, consequently, decrease of electron energy, leads to the saturation of $I_{\text {ion }}\left(I_{\mathrm{a}}\right)$. This is seen for indium $U_{\mathrm{a}}$ is just above the ionization potential $(5.786 \mathrm{eV}[15])$ for larger $I_{\mathrm{c}}$.

Dependence of $I_{\text {ion }}$ on the magnetic field was tested in order to find its optimal values. Both curves have their maxima near $10 \mathrm{mT}$. Let us note that the curve for the more volatile substance In has a broader peak than that for $\mathrm{Al}$ - such behavior was also observed for our previous type of ion source. Magnetic field from the external coil is used to compensate the field of spiral filament. It increases efficiency but only up to some level - this effect is hindered by the reduction of $U_{\mathrm{a}}$, as could be seen for indium.

Characteristics of the source were also determined for noble gases (Xe, Ne and He). As one can see in Fig. 4, the trends of the curves are similar to those for solids. The total extracted currents grow almost linearly with $I_{\mathrm{a}}$, the increase of $U_{\mathrm{a}}$ is also visible. High $I_{\mathrm{c}}$ is required to provide enough primary electrons. There is a rise of $I_{\text {tot }}$ with $I_{\mathrm{c}}$ in the case of $\mathrm{He}$ and Ne. Once again increasing $I_{\mathrm{c}}$ leads to the reduction of $U_{\mathrm{a}}$ and deterioration of ionization efficiency due to lowering energy of electrons. This effect is well pronounced in the case of Xe. In order to optimize performance of the source, the optimal electromagnet current has to be chosen for each gas - the curves have much broader peaks than in the case of solid feeding substances.
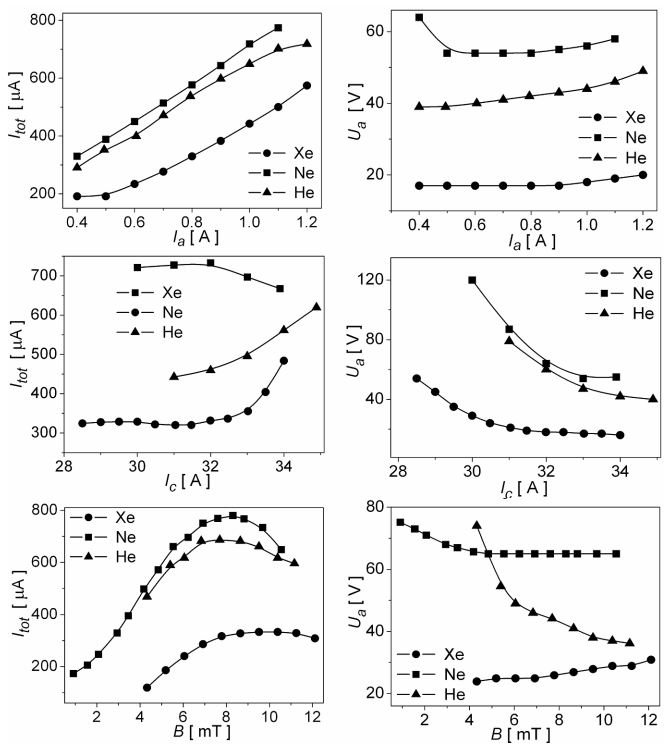

Fig. 4. Total extracted currents and $U_{\mathrm{a}}$ as functions of $I_{\mathrm{a}}, I_{\mathrm{c}}$ and $B$. Case of noble gases.

Other feeding substances, like $\mathrm{Bi}, \mathrm{As}, \mathrm{Sb}$ and the like were also used. The ion currents (e.g. $90 \mu \mathrm{A}$ of $\mathrm{Bi}^{+}$, $35 \mu \mathrm{A}$ of $\mathrm{Sb}$ ) were comparable or even better to those obtained using the cylindrical anode source [12] despite very low $I_{\mathrm{a}}$. It should be mentioned here that the source under some conditions (e.g. high $U_{\mathrm{a}}$ ) is capable of producing reasonable amounts of doubly charged ions - e.g. a current of $15 \mu \mathrm{A}$ of $\mathrm{Bi}^{++}$ions was measured when $U_{\mathrm{a}}$ was approximately $120 \mathrm{~V}$. High currents of molecular ions were also observed. In the case of antimony the current of $\mathrm{Sb}_{2}^{+}$ion $(25-30 \mu \mathrm{A})$ was comparable to that of $\mathrm{Sb}^{+}$ ions, giving opportunity of high dose implantations in a reasonable time.

\section{Conclusions}

A novel design of ion source with an internal evaporator heated by a spiral cathode filament and arc discharge has been presented. The source is able to produce much higher ion current intensities than in the case of our previous construction, due to the fact that the arc discharge region is as close as possible to the extraction orifice. The extracted $\mathrm{Al}^{+}$and $\mathrm{In}^{+}$and $\mathrm{Sb}^{+}$current intensities are $50 \mu \mathrm{A}, 70 \mu \mathrm{A}$ and $35 \mu \mathrm{A}$, respectively. Despite the fact that very low anode currents were used (up to $1.2 \mathrm{~A}$ ) these values are comparable with the parameters of a commercial hollow cathode source (HighVoltage 
Engineering model SO-55) [16]. One may expect that using an anode power supply capable of providing a current of 3-4 A will result in ion currents at least twice or three times larger than those presented in this paper.

The source is able to provide beams of molecular (like $\mathrm{Sb}_{2}^{+}$) and doubly charged ions. Other advantages of this sources are: simple maintenance and low power consumption (approximately 350-400 W). The hollow cathode ion source with internal evaporators enables high dose (up to $10^{17}$ ions per $\mathrm{cm}^{2}$ ) implantations with a variety of metallic and non-metallic solids.

\section{Acknowledgments}

This work is supported by Maria Curie-Skłodowska University in Lublin in the frame of the grant of the MCSU Rector from the Polish Ministry of Science and Higher Education funds.

\section{References}

[1] X. Ren, Z. Zhao, W. Zhao, Rev. Sci. Instrum. 79, $02 \mathrm{C} 717$ (2008).

[2] K. Potzger, S. Zhou, F. Eichhorn, M. Helm, W. Skorupa, A. Mücklich, J. Fassbender, J. Appl. Phys. 99, 063906 (2006).

[3] H. Zhang, Ion Sources, Springer-Verlag, Berlin 1999.

[4] L. Bischoff, J. Teichert, J. Phys. D, Appl. Phys. 33, L69 (2000).
[5] H. Waldmann, B. Martin, Nucl. Instrum. Methods Phys. Res. B 98, 532 (1995).

[6] G.D. Alton, G.D. Mills, J. Dellwo, Rev. Sci. Instrum. 65, 2006 (1994).

[7] J.R. Southon, M.L. Roberts, Nucl. Instr. Meth. Phys. Res. B 172, 257 (2000).

[8] Y.C. Feng, S.P. Wong, Nucl. Instrum. Methods Phys. Res. B 149, 195 (1999).

[9] J. Meldizon, A. Drozdziel, A. Latuszynski, S. Prucnal, K. Pyszniak, D. Maczka, Vacuum 70, 447 (2003).

[10] M. Rosiński, J. Badziak, F.P. Boody, S. Gammino, H. Hora, J. Krása, L. Láska, A.M. Mezzasalma, P. Parys, K. Rohlena, L. Torrisi, J. Ullschmied, J. Wołowski, E. Woryna, Vacuum 78, 435 (2005).

[11] A.A.I. Khalil, M.A. Gondal, Nucl. Instrum. Methods Phys. Res. B 267, 3356 (2009).

[12] M. Turek, S. Prucnal, A. Drozdziel, K. Pyszniak, Rev. Sci. Instrum. 80, 043304 (2009).

[13] M. Turek, S. Prucnal, K. Pyszniak, A. Drozdziel, Nucl. Instr. Meth. Phys. Res. B 269, 700 (2011).

[14] I.G. Brown, B. Feinberg, J.E. Galvin, J. Appl. Phys. 63, 4889 (1988).

[15] J.H.M. Neijzen, A. Donszelmann, Physica 106C, 271 (1981).

[16] http://www.highvolteng.com/media/Leaflets/ Model_SO-55_Ion_Source.pdf . 